\title{
Survey on present and potential instructional use of computers in psychology
}

\author{
DARRELL L. BUTLER and ANN M. KRING \\ Ball State University, Muncie, Indiana
}

\begin{abstract}
A survey of academic psychologists was taken to determine present use of computers in instruction, willingness to use good education software, and kinds of potential uses of computers in psychology courses. A majority of the respondents reported using computers in instruction. Respondents indicated substantial willingness to adopt computer-based courseware. Respondents believed that a variety of uses, including classroom demonstrations and student experiments, would facilitate student learning. The results of the survey are compared with the instructional modules the task force is developing.
\end{abstract}

The areas for which we are developing microcomputer tools were chosen as a result of two factors: our beliefs about the instructional computing interests of academic psychologists and our personal interests and expertise. The purpose of this paper is to explore further the interests of academic psychologists and to compare those interests with the goals that the task force has chosen. This exploration and comparison provides the first step in the evaluation of the project and may help to answer the important question, "Where do we (and others) go from here?"

A survey on instructional computer use in colleges and universities was completed in 1978-1979 (Castellan, 1982). In that study, psychology faculty indicated instructional computing needs in a number of content areas. The initial modules being developed by our group (Overview of Psychology, Methodology, Animal Learning, Memory \& Cognition, and Sensation \& Perception) are a subset of the areas identified in Castellan's survey. This suggests that the coverage is appropriate, but there is much to be done. Caution should be exercised in comparing the goals of the task force with Castellan's findings. First, many aspects of computer capability and availability have changed since the late 1970s. And the availability of inexpensive microcomputers has increased substantially. Second, faculty knowledge and computer sophistication have grown. Most of the respondents in Castellan's study reported plans to increase their use of computers.

The changes since 1978 suggested a need for an updated survey. Aaronson (1983) surveyed 12 ongoing CAI projects and reported valuable information for instructors considering developing CAI. However, the survey provided an intense evaluation of several projects and resulted in a rather narrow representation of present instructional uses of computers. Also, the survey did not evaluate psychologists' willingness to

The authors' mailing address is: Department of Psychological Science, Ball State University, Muncie, IN 47306. purchase good educational software, and did not measure the various uses that software purchasers deemed important.

In an effort to explore these issues, we mailed questionnaires to all psychology faculty at five colleges and universities (see Table 1). It is obvious that the institutional sample was limited. The universities were not selected randomly; the schools are the home institutions of the members of our task force. However, the use and potential use of computers were surveyed for a variety of areas within psychology. The list of areas included in the questionnaire was derived from chapter headings in six widely used introduction-to-psychology textbooks. The resulting list (12 areas) was similar to, but slightly larger than, the list (9 areas) reported in a recent study of computer use in psychology (Castellan, 1982). Respondents answered questions in three additional areas: stress, developmental psychology, and "others."

Fifty-one percent (a total of 57 individuals), of the faculty responded to the questionnaire. The return rate is low, but it is similar to that obtained in other recent surveys.

\section{SURVEY RESULTS}

All results are reported as the percentage of individuals responding to the survey. This method may overestimate faculty use and interest; conservative estimates result

Table 1

Faculty, Respondents, and Degree Programs of Surveyed Universities

\begin{tabular}{cccc}
\hline School & $\begin{array}{c}\text { Size of } \\
\text { Faculty }\end{array}$ & $\begin{array}{c}\text { Number of } \\
\text { Respondents }\end{array}$ & $\begin{array}{c}\text { Highest } \\
\text { Degree Granted }\end{array}$ \\
\hline 1 & 38 & 16 & PhD \\
2 & 27 & 16 & PhD \\
3 & 20 & 9 & PhD \\
4 & 21 & 13 & MA \\
5 & 6 & 3 & BA \\
\hline
\end{tabular}


by halving the percentages. The conservative estimate approximates a percentage of the total group surveyed, rather than the percentage of the respondents.

\section{Present Use of Computers}

Fifty-one percent of the respondents used computers in at least one course; $31 \%$ reported using computers in more than one course.

The reported use of computers is greater in undergraduate $(44 \%)$ than in graduate $(19 \%)$ courses. This is due primarily to the number of respondents who use computers in undergraduate statistics, undergraduate methodology, and introduction to psychology. Table 2 shows the present use by course area. Castellan (1982) also found that computers were used more in these three areas than in other areas. Other factors responsible for the greater reported use of computers in the undergraduate curriculum are that not all instructors in the survey taught graduate courses (see Table 1), and instructors typically teach more undergraduate courses than graduate courses.

Table 3 shows that respondents differed in their uses of computers. The most commonly reported use was in student laboratories. Several instructors indicated that students used the computer primarily for data

Table 2

Present and Potential Use (in Percent) of Computers in Undergraduate and Graduate Courses

\begin{tabular}{lrrrrr} 
& \multicolumn{2}{c}{ Undergraduate } & & \multicolumn{2}{c}{ Graduate } \\
\cline { 2 - 3 } \multicolumn{1}{c}{ Area } & $\begin{array}{c}\text { Pres- } \\
\text { ent }\end{array}$ & $\begin{array}{c}\text { Poten- } \\
\text { tial }\end{array}$ & & $\begin{array}{c}\text { Pres- } \\
\text { ent }\end{array}$ & $\begin{array}{c}\text { Poten- } \\
\text { tial }\end{array}$ \\
\hline Statistics & 19 & 75 & 5 & 61 \\
Methodology & 11 & 53 & 5 & 40 \\
Introduction to Psychology & 12 & 40 & 2 & 19 \\
Test/Measures & 4 & 61 & 4 & 44 \\
Sensation/Perception & 4 & 56 & 2 & 42 \\
Learning & 5 & 54 & 4 & 42 \\
Memory/Cognition & 5 & 56 & 4 & 44 \\
Physiology & 0 & 40 & 2 & 30 \\
Language/Speech & 5 & 37 & 2 & 35 \\
Social & 5 & 35 & & 26 \\
Personality & 2 & 30 & & 26 \\
Abnormal/Therapy & 2 & 30 & 5 & 33 \\
Motivation/Emotion & 0 & 33 & 0 & 30 \\
Stress & 2 & 7 & 0 & 0 \\
Developmental & 0 & 0 & 0 & 2 \\
Mean* & 6 & 45 & 3 & 36 \\
\hline
\end{tabular}

${ }^{*}$ Not including stress and developmental.

Table 3

Types of Computer Uses (in Percent)

\begin{tabular}{lcc}
\multicolumn{1}{c}{ Type of Use } & Present & Potential \\
\hline Student Laboratories & 33 & 86 \\
Class Demonstration & 26 & 68 \\
Student Homework & 19 & 61 \\
Individual Student Projects & 21 & 58 \\
Exams & 19 & 33 \\
Other & 4 & 4 \\
\hline
\end{tabular}

analysis and for running experiments. Also, faculty reported using computers more for class demonstrations than for automated testing or test scoring.

\section{Willingness to Use Software}

The majority $(81 \%)$ of the respondents indicated that they would use good educational software if available. Reasons for this use are that:

(1) a student's learning pace can be individualized;

(2) computers can provide efficient techniques for presenting basic course concepts and information;

(3) computers may bring about greater student interest and motivation;

(4) immediate feedback can be provided;

(5) computers may permit demonstrations (e.g., motion) that are difficult to do using other techniques;

(6) computers may save the instructor time.

Nine percent of the respondents indicated that they would not use good educational software for instructional purposes. The reasons were that: the necessary hardware was not available, especially for large classes, and it was difficult to integrate computers into existing well-designed courses. These reasons are similar to the two major constraints upon computer usage reported in Castellan's (1982) study, that is, lack of time and lack of equipment.

\section{Potential Uses of Computers}

Respondents indicated that student learning could be facilitated if computers were used to a much greater extent than is presently the case. A summary of responses concerning present and potential use is given in Table 2. Mean increases from present use to potential use are calculated separately for undergraduate and graduate course areas. The difference between present use and potential use is especially large for undergraduate and graduate statistics; the mean increase is $56 \%$ for each. The areas other than statistics that showed above average increases are methodology, introduction to psychology, tests/measures, sensation/perception, learning, memory/cognition, and physiology for undergraduates and methodology, tests/measures, sensation/ perception, learning, memory/cognition, and language/ speech for graduates.

Certain types of computer use were seen as more facilitative than others to student learning (see Table 3 ). Most respondents (86\%) indicated that computer use in student laboratories would be facilitative. About twothirds of the respondents believed that student learning would also be aided by computerizing class demonstrations, student homework, and individual student projects. Only one-third of the respondents indicated that computerized exams would be helpful, and more than half of these third currently used computerized exams. The results concerning computerized examinations suggest that such exams are used by instructors for administrative efficiency and not directly as aids to student learning. 


\section{COMPARING SURVEY TO MODULES}

Respondents to the survey indicated that the use of computers in statistics and methodology courses could be especially advantageous to student learning. Traditionally, statistics has been important in the psychology curriculum, as well as in many other sciences. In recent years, there has been an increase in the number of statistical computer programs (see Eamon, 1983, and Levy, 1983). Since many scientific fields use statistics, the availability of good programs will probably continue to increase. The availability of methodology programs useful in psychology (Eamon, 1983; Fazio \& Backler, 1983 ) is also increasing, although not as rapidly as for statistics.

Modules developed by the task group provide an introduction to statistics and methods. These modules should be appropriate for both introduction-to-psychology and statistics courses. One of the advantages over presently available programs is their similarity in structure, concept, and function to our other psychology modules.

Three of the content areas that respondents reported to be substantially facilitated by the use of computers, that is, sensation/perception, learning, and memory/ cognition, match the titles of our modules. There are some computer programs available in psychology for instruction in these areas, but these are designed almost exclusively for use by students in laboratory courses (see Eamon, 1983). In contrast, the task force modules are designed to have a variety of uses, to permit instructors to demonstrate phenomena in class (i.e., electronic chalkboard, see Spivey, 1984) and allow students to study and explore various concepts and phenomena. This flexibility is consistent with the results of the survey reported in this paper: Class demonstrations, student laboratories, student homework, and individualized student projects were all judged to be important uses of computers to facilitate student learning.

Several areas in which respondents believed computer usage could be facilitative do not coincide with the development of modules by the present effort. As a result of limited resources, we could not develop modules in all areas believed to be useful. Thus, in this initial effort we chose to develop modules in those areas in which the task force had the greatest expertise. For example, tests and measurements is an area judged facilitative by respondents but not matched by any of our modules. Although courses in tests and measurements often put a strong emphasis on statistics, they are not limited to introductory statistical concepts. Two other areas that respondents believed computers could be facilitative-physiology (undergraduate) and language/ speech (graduate)-are not part of the task group modular scheme. As far as we know, few computer programs are available for these areas.

\section{SUMMARY}

It appears that our modules closely match the interests of many academic psychologists. The topic areas and the types of uses chosen for the initial modules appear to be compatible with the interests and needs of the survey respondents and, we believe, of a sizable proportion of academic psychologists. We hope that psychologists with personal interests and expertise in other needed areas, especially tests and measurements, physiology, and language and speech, will develop modules. The general framework and principles discussed in this symposium may serve as a guide to those attempting to develop such modules.

\section{REFERENCES}

Aaronson, D. (1983). What's happening in CAI: A survey of ongoing projects. Behavior Research Methods \& Instrumentation, 15, 262-269.

Cagtellan, N. J. (1982). Computers in psychology: A survey of instructional applications. Behavior Research Methods \& Instrumentation, 14, 198-202.

EAMON, D. B. (1983). Microcomputer programs for instruction in psychology: A sampler. Collegiate Microcomputer, 1, 11-18.

Fazio, R. H., \& Backlen, M. H. (1983). Computer lessons for a social psychology research methods course. Behavior Research Methods \& Instrumentation, 15, 135-137.

Levy, C. M. (1983). Microcomputer-based tutorials for teaching statistics. Behavior Research Methods \& Instrumentation, 15, 127-129.

Spivey, J. E., \& JaCkson-Smith, P. The electronic chalkboard. Behavior Research Methods, Instruments, \& Computers, 16, 172-175. 